\title{
Surgically revascularized intercoronary communication: an extremely rare case of an open-ended circulation pattern
}

\author{
Elif Coşkun ${ }^{1}$, Mustafa Büyükateş² \\ ${ }^{1}$ Department of Cardiovascular Surgery, Medical Faculty of Bülent Ecevit University, Zonguldak, Turkey \\ ${ }^{2}$ Department of Cardiovascular Surgery, Medical Faculty of Selçuk University, Konya, Turkey \\ Received: October 18, 2016 Accepted: January 23, 2017 Published online: April 17, 2017
}

\section{ABSTRACT}

Coronary artery abnormalities are congenital deformities including the origin, tract, and structure of the coronary arteries. Intercoronary communicating vessels are the conduits between two or more coronary arteries enabling either one- or two-way blood flow and they are exceptionally rare. In this article, we present a 54-year-old male case of coronary artery abnormality with typical chest pain and exertional angina and discuss surgical revascularization in the light of literature data.

Keywords: Coronary vessel abnormality; intercoronary communication; revascularization; surgery.

Intercoronary communication (ICC), which is extremely rare, was first described by Cheng in 1972. ${ }^{[1]}$ This type of communication between normal coronary arteries is congenital with a diagnostic coronary angiography incidence of $0.05 \% .{ }^{[2]}$

Two types have been described: communication between the left anterior descending (LAD) and posterior descending artery (PDA) in the distal interventricular groove, and communication between the circumflex artery $(\mathrm{Cx})$ and right coronary artery $(\mathrm{RCA})$ in the posterior atrioventricular groove. ${ }^{[3]}$ The communication between the LAD and RCA in the distal PDA branch is extremely rare. ${ }^{[3]}$ Herein, we report a 54-year-old male case of coronary artery abnormality with typical chest pain and exertional angina and discuss surgical revascularization in the light of literature data.

\section{CASE REPORT}

A 54-year-old male patient was admitted to our cardiology outpatient clinic with complaints of typical chest pain and exertional angina. Physical examination and laboratory analysis showed no pathology. His medical history revealed that he was a current smoker, which was a risk factor for heart disease. Transthoracic echocardiography demonstrated an ejection fraction (EF) of $60 \%$, left ventricular diastolic relaxation abnormality (grade 1$)$, left atrial dilation $(4.0 \mathrm{~cm})$, and minimal mitral regurgitation $\left(1^{\circ} \mathrm{MR}\right)$. Myocardial perfusion scintigraphy showed reversible hyperperfusion in the apical, basal, lateral and inferolateral walls, and hypokinesia in the apical, lateral and inferolateral walls. Coronary angiography showed a severe lesion (80 to $90 \%$ ) in the LAD before the second diagonal branch and a severe lesion in the proximal branch of the RCA (70 to $80 \%)$. In addition, a communication was detected between the RCA and LAD artery branches (Figure 1). This communication competed between two arteries in both diastoles.

A written informed consent was obtained from the patient. He, then, underwent elective surgery with median sternotomy through aorto-atrial cannulation under cardiopulmonary bypass. Antegrade cold blood cardioplegia was applied in on-pump surgery. Intraoperatively, ICC was clearly detected. Threevessel (RCA-saphenous vein, second diagonal artery-saphenous vein, and LAD artery-left internal mammary artery) coronary artery bypass grafting $(\mathrm{CABG})$ was performed. In the postoperative period, the patient was hemodynamically stable, and he was uneventfully discharged with acetylsalicylic acid

Corresponding author: Elif Coşkun, MD. Bülent Ecevit Üniversitesi Tıp Fakültesi Kalp ve Damar Cerrahisi Anabilim Dalı, 67600 Esenköy, Kozlu, Zonguldak, Turkey.

Tel: +90 533 - 8186913 e-mail: drelfco@gmail.com 


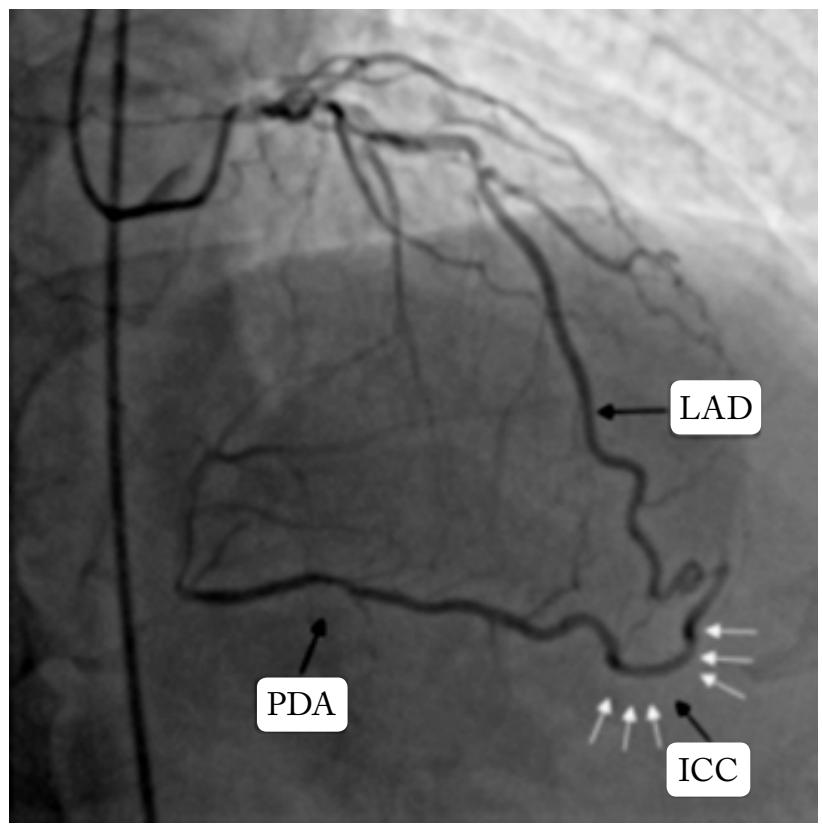

Figure 1. A coronary angiographic view showing intercoronary communication between the LAD artery and RCA in the distal PDA branch.

LAD: Left anterior descending; RCA: Right coronary artery; PDA: Posterior descending artery; ICC: Intercoronary communication.

$300 \mathrm{mg}$ daily after one week of surgery. At three months, he is still uneventful.

\section{DISCUSSION}

Intercoronary communication is congenital in origin, and it has been suggested that a defective embryological development allowed the existing intercoronary channel to remain prominent. ${ }^{[4]}$

As it is a congenital malformation, it can be misdiagnosed as collateral circulation secondary to obstructive coronary artery disease. ${ }^{[5]}$ Intercoronary collaterals are tortoise, typically smaller than $1 \mathrm{~mm}$ with a very meandering course. Histologically, they are composed of endothelium supported by weak collagens, and muscular and elastic fibers. ${ }^{[2,3]} \mathrm{On}$ the other hand, intercoronary communications are typically larger in size $(\geq 1 \mathrm{~mm})$, single, and straight vessels and are arterioles which carry the muscular structure of the epicardial vessels. ${ }^{[2,3]}$

It is well-established that the main goal of CABG is to treat reversible ischemia due to coronary artery stenosis. In case of an ICC, which is extremely rare, treatment, intervention, and follow-up are of utmost importance.
On the other hand, the functional value of this type of abnormality still remains to be elucidated. These connections may play a protective role for myocardium, if the coronary artery obstruction develops in one of the two connecting vessels. ${ }^{[6]}$ This abnormality, also known as an open-ended coronary circulation pattern, is considered to be protective for the myocardium against occlusive coronary damage. ${ }^{[6]}$ However, some authors have suggested that one-way flow, as confirmed by coronary angiography, may result in insufficient perfusion, thereby, leading to coronary steal phenomenon and myocardial ischemia. ${ }^{[7]}$

In our case, two-way flow was maintained through contrast injection into the right or left coronary artery. It was evident that two-way intercoronary blood flow, which led to a competition between two arteries in both diastoles, was seen and that it was not the communication between the collaterals between the RCA and LDA artery branches. We believe that the absence of isolated RCA stenosis induced competition phenomenon, rather than steal phenomenon in our case in whom the abnormality originated from an atherosclerotic process. In addition, coronary angiography showed severe atherosclerotic plaques in the RCA and LAD artery, while myocardial perfusion scintigraphy revealed reversible ischemic regions. Based on these imaging findings, both arteries were bypassed and only the left internal mammary artery was used to avoid sternal instability. On the other hand, it is still controversial that which arteries are bypassed, which grafts are selected, and how the selected grafts affect the ICC. Based on our experience, we recommend that the atherosclerotic processes should be investigated, vessels with ICC should be examined, and steal/competition phenomena should be further evaluated.

In conclusion, the uncommon presence of an open-ended coronary circulation pattern is known in patients with and without coronary artery narrowing. In the presence of obstructive coronary artery disease, it can be confused with collateral circulation, although both share distinct anatomical, histological, and functional structures. Although rare, it may cause an incorrect diagnosis and treatment, if left unrecognized; therefore, clinicians should be careful.

\section{Declaration of conflicting interests}

The authors declared no conflicts of interest with respect to the authorship and/or publication of this article. 


\section{Funding}

The authors received no financial support for the research and/or authorship of this article.

\section{REFERENCES}

1. Cheng TO. Arteriographic demonstration of intercoronary arterial anastomosis in a living man without coronary artery disease. Angiology 1972;23:76-88.

2. Hines BA, Brandt PW, Agnew TM. Unusual intercoronary artery communication: a case report. Cardiovasc Intervent Radiol 1981;4:259-63.

3. Donaldson RF, Isner JM. Intercoronary continuity: an anatomic basis for bidirectional coronary blood flow distinct from coronary collaterals. Am J Cardiol 1984;53:351-2.

4. Reig J, Jornet A, Petit M. Direct connection between the coronary arteries in the human heart. Intercoronary arterial continuity. Angiology 1995;46:235-42.

5. Fournier JA, Cortacero JA, Díaz de la Llera L, Sánchez A, Arana E, Morán JE. Distal intercoronary communication. A case report and medical literature review. Rev Esp Cardiol 2003;56:1026-8. [Abstract]

6. Ozlü MF, Ozcan F, Sen N, Cağlı K. An intercoronary connection serving as a safety valve for the left ventricle. Turk Kardiyol Dern Ars 2010;38:416-8.

7. Shashanka C, Rajasekhar D, Vanajakshamma V, Kumar MLS. A rare coronary anomaly: intercoronary communication between the circumflex and right coronary arteries. JICC 2012;2:167-9. 